\title{
Anal Carcinoma Therapy: Can We Improve on 5-Fluorouracil/Mitomycin/Radiotherapy?
}

\author{
Yixing Jiang, MD, PhD; ${ }^{* *}$ Heath Mackley, MD;* Hua Cheng, MD, PhD; and Jaffer A. Ajani, MD; ${ }^{\mathrm{b}}$ Hershey,
} Pennsylvania, and Houston, Texas

Key Words

5-FU, mitomycin, radiation, anal cancer

\begin{abstract}
Use of definitive chemoradiation as primary therapy for locoregional squamous cell carcinoma of the anal canal has been the standard approach in the United States since the 1980s. Over the past several years, phase III studies have shown that combination mitomycin C (MMC) and 5-fluorouracil (5-FU) concurrent with radiotherapy had better outcomes than radiotherapy alone or 5-FU with radiotherapy. Two recent phase III studies using diverse treatment strategies showed that cisplatin and 5-FU were not superior to 5-FU and MMC; in one of the trials, use of cisplatin-based chemoradiation resulted in a higher rate of colostomy compared with mitomycin-based chemoradiation. MMC and 5-FU concurrent with radiotherapy remains standard care. Further improvement is likely depending on an increased understanding of the molecular biology of anal carcinoma and the addition of relevant biologic agents to chemoradiation to overcome chemoradiation resistance. (JNCCN 2010;8:135-144)
\end{abstract}

Squamous cell carcinoma of the anal canal is a rare disease, with incidence of approximately 1.6 per 100,000 based on SEER data from 2002 to $2006 .{ }^{1}$ Over the past 2 decades, chemoradiation has become the cornerstone treatment in the management of anal cancer. However,

\footnotetext{
From aPenn State College of Medicine, Penn State Cancer Institute, Hershey, Pennsylvania, and 'bepartment of Gastrointestinal Oncology, University of Texas M. D. Anderson Cancer Center, Houston, Texas.

*Made equal contributions to the manuscript.

Submitted August 7, 2009; accepted for publication November 9, 2009.

The authors have disclosed that they have no financial interests, arrangements, or affiliations with the manufacturers of any products discussed in the article or their competitors.

Correspondence: Jaffer A. Ajani, MD, Department of

Gastrointestinal Oncology, University of Texas M. D. Anderson

Cancer Center, 1515 Holcombe Boulevard, Houston, TX 77030

E-mail: jajani@mdanderson.org
}

treatment failure is frequent in patients with bulky primary tumors and regional lymphadenopathy. To improve the efficacy of chemoradiation, several approaches have been investigated, including changing mitomycin-based chemotherapy to a platinum-based regimen, increasing radiation dosage, and using induction chemotherapy or maintenance systemic chemotherapy. This article summarizes and describes current approaches in the management of squamous cell carcinoma of the anal canal.

\section{The Evolving Role of Chemoradiation in Locoregionally Confined Disease}

\section{Role of 5-Fluorouracil and Mitomycin C in Chemoradiation}

Abdominoperineal resection was the foundation in the management of locoregionally confined squamous cell carcinoma of the anal canal in the 1970s. The 5-year survival for all stages in surgical series ranges from $50 \%$ to $70 \% .^{2,3}$ Survival decreased significantly with larger tumors, muscle invasion, and positive lymph nodes. Beahrs and Wilson ${ }^{3}$ analyzed 204 patients with anal neoplasms treated at the Mayo Clinic from 1950 to 1970. Of these patients, 113 had squamous histology; 84 were analyzed for survival. Most patients were treated with abdominoperineal resection and 10 with local resection. The 5 -year survival was $57.8 \%$. A subgroup analysis showed that the 5-year survival for superficial tumors was $90.9 \%$, and was reduced to $57.5 \%$ for muscle-invasive, node-negative tumors. The 5 -year survival further decreased to $31.8 \%$ in muscle-invasive, node-positive tumors. The work by Beahrs and Wilson ${ }^{3}$ showed that surgical resection is effective in treating locoregionally confined anal cancer. Other investigators have reported similar surgical outcomes, 4,5 with survival strongly as- 
Jiang et al.

sociated with disease stage. However, the procedure requires a permanent colostomy.

In 1983, Nigro et $a .^{6}$ showed that a complete pathologic response could be achieved with the combination of mitomycin $\mathrm{C}$ (MMC), 5-fluorouracil (5$\mathrm{FU}$ ), and 30 Gy of pelvic radiotherapy before surgical resection. This observation initiated a shift in the management paradigm from radical surgery to an organ preservation approach, but the optimal treatment regimen remained controversial. Several large studies were subsequently conducted to compare the efficacy of radiation and chemoradiation in anal cancer.

Two European prospective randomized trials compared the efficacies of radiotherapy alone versus chemoradiation in locoregionally confined anal cancer. The United Kingdom Coordinating Committee on Cancer Research (UKCCCR) Anal Cancer Working Group compared radiotherapy alone with chemoradiation using 5-FU/MMC. ${ }^{7}$ A total of 585 patients were randomized to $45 \mathrm{~Gy}$ of radiotherapy with or without concurrent 5-FU/MMC. The complete clinical response rates were similar between the groups (39\% for chemoradiation and 30\% for radiotherapy alone; $P=.08$ ). However, the 3 -year local failure rate was significantly lower in the chemoradiation group (39\% for chemoradiation and 61\% for radiotherapy alone; $P<.0001$ ). Local failure was defined as persistent disease more than 6 weeks after initial therapy, colostomy for recurrent disease, or colostomy for treatment-related morbidity. Cancer-specific survival was also superior in the chemoradiation arm (relative risk [RR], 0.71; $P=.02$ ). Nonetheless, no significant difference was seen in overall survival between the treatment arms. Approximately 40\% of patients died of distant metastases (distant metastasis alone or with local recurrence).

Bartelink et $\mathrm{al}^{8}{ }^{8}$ confirmed that the addition of 5-FU to radiotherapy is superior to radiotherapy alone from a study by the EORTC 22861. A total of 110 patients were randomized to either radiotherapy alone or combination chemotherapy and radiotherapy delivered in 2 periods. Patients were first given 45 Gy of radiation over 5 weeks ( 1.8 Gy per faction), with chemotherapy administered concurrently with radiation. This consisted of a single $15 \mathrm{mg} / \mathrm{m}^{2}$ dose of $\mathrm{MMC}$ given on day 1 and a daily dose of 5-FU at $750 \mathrm{mg} /$ $\mathrm{m}^{2}$ given as a continuous infusion on days 1 through 5 and 29 through 33. Clinical response was then assessed after 6 weeks of resting, after which patients who experienced a clinical complete response were given a boost of $15 \mathrm{~Gy}$ of radiation and those with a partial response a boost of $20 \mathrm{~Gy}$. Patients with clear disease progression were offered salvage surgery.

This study showed a significant increase in complete clinical response in the chemoradiation group ( $80 \%$ for chemoradiation vs. $54 \%$ for radiation alone). The higher remission rate translated into a better local control and lower permanent colostomy rate at 5-year follow-up. Toxicity profiles were similar between the treatment arms except that anal ulcers were more commonly observed in the combined modality group.

The United States Intergroup prospectively randomized trial (RTOG 87-04/ECOG 1289) evaluated 5-FU chemoradiation versus 5-FU/MMC chemoradiation. ${ }^{9}$ Patients in the study were treated with either chemotherapy regimen with 45 to 50.4 Gy of pelvic radiotherapy using a shrinking field technique. A salvage plan was integrated into the protocol. Primary tumors were assessed with a biopsy 4 to 6 weeks after the completion of chemoradiation. Patients who did not experience a complete response received an additional cycle of cisplatin and 5-FU with 9 Gy of radiotherapy.

Results showed that 28 patients had biopsypositive disease, of which 25 patients received salvage cisplatin, 5-FU, and radiation. Of the 22 evaluable patients, 12 achieved a complete response with negative biopsy; 10 patients had persistent disease and were offered surgical resection. Patients with persistent disease after the salvage chemoradiation were offered abdominoperineal resection. The colostomy rate at 4 years was significantly lower in the MMC-containing arm (9\% vs. $22 \% ; P=.002)$, as was the local failure rate $(16 \%$ vs. $34 \% ; P=.0008)$. No difference was seen in the clinical response rate between the arms. The disease-free survival at 4 years was superior in patients treated with MMC and 5-FU chemoradiation (73\% vs. $51 \% ; P=.0003)$. No statistical difference in overall survival was detected between the treatment arms, although a trend of survival benefit was seen toward the MMC group ( $76 \%$ vs $67 \%$; $=.31$ ). Both hematologic and nonhematologic toxicities were significantly increased with the addition of MMC.

Radiation dose intensification, with a planned split course to improve tolerability, was also evaluated to improve the efficacy of chemoradiation in 2 phase II studies. Bosset et al. ${ }^{10}$ reported a single-arm phase II study sponsored by the EORTC (EORTC 
22953). The study included a total of 43 patients. The treatment regimen included a 16-day break between treatment courses. In the first course, patients were given MMC $\left(10 \mathrm{mg} / \mathrm{m}^{2}\right)$ on day 1 , a daily 5 -FU infusion $\left(200 \mathrm{mg} / \mathrm{m}^{2}\right.$ per day), and 36 Gy of pelvic radiation over 20 fractions. Those with disease progression were offered a salvage resection. Those experiencing a clinical complete or partial response continued to the second course of therapy, in which an additional boost dose of 23.4 Gy was delivered with daily infusional 5-FU and MMC on day 17. Patients in the study received a total of 59.6 Gy. The authors described a superior local control rate (88\% EORTC 22953 vs. $68 \%$ EORTC 22861) and colostomy-free rate $(81 \%$ EORTC 22953 vs. 72\% EORTC 22861). However, that comparison is primarily hypothesis-generating and should be interpreted with caution.

However, RTOG 92-08 did not reveal similar findings when evaluating the efficacy of a higher radiation dose in MMC-based chemoradiation. ${ }^{11}$ In this study, all patients received MMC and 5-FU with a total of 59.6 Gy of pelvic radiotherapy using a shrinking field technique. The study also incorporated a planned 2-week treatment break, which resulted in a decrease in the acute skin toxicity. However, the colostomy rate was higher than that of RTOG 87-04 (23\% vs. $6 \%$ at 1 year). Although the results were recently updated, the final conclusion remains the same. ${ }^{12}$ In a post-hoc subgroup analysis, a trend of better local control was seen in patients who did not have the treatment break. However, the size of the 2 groups was too small for the difference to be statistically significant.

In summary, these studies show that an organ preservation approach with chemoradiation is feasible, safe, and relatively tolerable, establishing MMC and 5-FU with radiotherapy as the standard of care for locoregionally confined anal cancer. However, incomplete responses and recurrences are still common in T3-4 and node-positive disease. Higher radiation doses, possibly using a planned split course, could potentially improve outcomes in MMC-based chemotherapy. However, in the absence of a prospective phase III study showing this, it remains nonstandard.

\section{Role of Cisplatin in Chemoradiation}

Over the past decade, other chemotherapy agents have been studied to try to improve chemoradiation outcomes. Cisplatin has been used successfully for treating mucosal squamous cell carcinoma of the head and neck, esophagus, and cervix. Doci et al. ${ }^{13}$ treated 35 patients who had anal cancer with cisplatin and 5-FU concurrent with radiation. A median of 57 Gy of pelvic radiation was given with 2 cycles of chemotherapy. The authors compared results with their historical experience using 5-FU and MMC radiotherapy. The local control rate was $6 \%$ higher using cisplatin-based chemoradiation and the toxicity profile was also favorable. This finding was encouraging and led to further study of this approach.

Subsequently, RTOG 98-11 prospectively compared chemoradiation regimens of cisplatin/5-FU and $\mathrm{MMC} / 5-\mathrm{FU} .{ }^{14}$ A total of 644 patients were randomized to either MMC or cisplatin. All patients were treated with definitive chemoradiation with a total dose of 45 to 59 Gy using a shrinking field technique. Patients in the cisplatin arm received 2 cycles of cisplatin and 5-FU induction chemotherapy before undergoing definitive chemoradiation. The results showed that the regimens were similar in 5-year disease-free survival $(60 \%$ in the MMC arm vs. $54 \%$ in the cisplatin arm; $P=.17$ ) and 5 -year overall survival (75\% in the $\mathrm{MMC}$ arm vs. $70 \%$ in the cisplatin arm; $P=.1)$. However, the colostomy rate was significantly higher in the cisplatin arm (19\% vs. $10 \% ; P=.02)$. The rate of distant metastases was not reduced with the 2 induction cycles of cisplatin and 5-FU (19\% vs. $15 \%$, respectively).

In a recent randomized phase II study (EORTC 22011-40014), Matzinger et al..$^{15}$ assessed the efficacy of combination MMC and cisplatin with radiotherapy. The treatment schema is similar to EORTC 22861, with 2 treatment courses and a 16-day break. A superior overall response rate was achieved in the cisplatin/MMC arm (91.9\% vs. $79.5 \%)$. Progressionfree survival was also improved in the experimental group $(94.2 \%$ vs. $76.3 \%)$ ). The toxicity was similar between the arms except with hematologic toxicities. However, treatment compliance was much lower in the MMC/cisplatin group. This approach must be further evaluated in a phase III study.

\section{Role of Other Agents in Chemoradiation}

Targeted agents, such as cetuximab, a monoclonal chimeric antibody against the epidermal growth factor receptor (EGFR), have been shown to be effective in combination with radiotherapy in treating squamous cell carcinoma of the head and neck. ${ }^{16} \mathrm{~A}$ small phase I study of patients with anal cancer showed that the addition of cetuximab to cisplatin and 5-FU chemoradiation is safe and feasible. ${ }^{17}$ The study enrolled patients 
Jiang et al.

with relatively advanced disease (T2N2-3, T3NO-3, and $\mathrm{T} 4 \mathrm{NO}$ ). A $78 \%$ pathologic complete response was described.

Oxaliplatin, a third-generation platinum agent, has been evaluated in this disease. A single-institution phase II study recently reported that the combination of oxaliplatin and capecitabine is reasonably well tolerated, with $91 \%$ to $100 \%$ response rates. ${ }^{18} \mathrm{Al}$ though the follow-up was short, the colostomy-free rate was $100 \%$. The results are promising and warrant further evaluation.

Other cytotoxic agents effective against mucosal squamous cell carcinomas of other sites could also potentially be efficacious. For example, gemcitabine and paclitaxel are often used to treat advanced squamous cell carcinoma of the lung, head and neck, esophagus, and cervix, either as single-agent treatment or in combination with other agents. Incorporating these cytoxic agents, alone or in combination with targeted agents, into novel chemoradiation regimens for treating anal cancer could be evaluated in future trials.

\section{Role of Systemic Chemotherapy}

The addition of maintenance chemotherapy to improve efficacy and survival was also studied by other investigators. James et al. ${ }^{19}$ reported a pilot phase II study from the UKCCCR using MMC, 5-FU, and cisplatin as radiosensitizers and as a maintenance chemotherapy regimen. However, the regimen was found to be too toxic and few patients were able to complete the therapy. Recently, James et al..$^{20}$ presented the results of the ACT II study at the 2009 ASCO annual meeting. This study is the largest randomized study in anal cancer. A total of 940 patients in the study were randomized to receive either cisplatin- or MMC-based chemoradiation. MMC was given at $12 \mathrm{mg} / \mathrm{m}^{2}$ on day 1 only, in contrast to RTOG 98-11, which gave $10 \mathrm{mg} / \mathrm{m}^{2}$ on days 1 and 29). No radiation break was planned in the study. A total dose of 50.4 Gy of radiation was administered. After chemoradiation, patients were randomized to either observation or maintenance therapy with cisplatin and 5-FU. The clinical complete response rates were almost identical among patients in both arms (94\% in MMC vs. 95\% in cisplatin). Furthermore, no difference was seen in disease-free (hazard ratio [HR], 0.89; 95\% CI, 0.68, 1.18; $P=.42$ ) and overall survival between the observation and maintenance groups (HR, 0.79; 95\% CI, 0.56, 1.12; $P=.19$ ). The study results suggest that cisplatin- and MMCcontaining chemoradiation regimens achieve similar results, and that addition of adjuvant chemotherapy did not have survival advantage.

Induction chemotherapy followed by chemoradiation has been evaluated further by United States and European groups. Conroy et al. ${ }^{21}$ recently reported the final data analysis of the ACCORD 03 study. The study randomized a total of 307 patients in a $2 \times 2$ factorial fashion to address the role of induction chemotherapy ( 2 cycles of cisplatin and 5-FU) followed by standard-dose pelvic chemoradiation (with 5-FU and cisplatin) with or without a boost of 15 Gy. At a median follow-up of 43 months, the overall local failure was $28 \%$, without significant differences between the groups. The 3-year colostomy-free survival (overall $83 \%$ ), which was the primary end point of the study, was similar across all 4 arms. The 3 -year overall survival was $78 \%$, which was also similar among all treatment groups. In this study, neither induction chemotherapy nor radiation dose-intensification improved the overall or disease-free survival compared with standard chemoradiation.

CALGB 9281 was a phase II study that treated patients with locally advanced disease (T3-4, bulky $\mathrm{N} 2$ or N3) with induction chemotherapy of 2 cycles of cisplatin and 5-FU followed by MMC and 5-FU chemoradiation. $^{22}$ Those with positive residual disease received an extra boost of radiotherapy to a dose of 9 Gy, with cisplatin and 5-FU as radiosensitizers. After a median follow-up of 4 years, overall and disease-free survival rates of $8 \%$ and $61 \%$ were reached, respectively.

The concept of adjuvant systemic chemotherapy has been proven effective in many other solid tumors. However, this approach has been disappointing in anal cancer. Three phase III studies (ACT II, RTOG 98-11, and ACCORD 03) showed no benefit associated with systemic therapy given before or after chemoradiation. A couple of potential mechanisms have been postulated to explain this finding: induction chemotherapy may have changed the sensitivity of tumor cells to subsequent chemoradiation, or the biology of anal cancer may be very different from squamous cell carcinoma of other organs.

\section{Conclusions}

Phase III studies showed that MMC/5-FU chemoradiation provides the best results for locoregionally confined anal cancer. Cisplatin/5-FU chemoradiation provides a similar overall survival to MMC/5-FU. However, the colostomy rate is higher in the cisplatin group. 
Anal Carcinoma Therapy

Currently, 5-FU/MMC with continuous radiation to a dose of 45 to 59 Gy remains standard practice in the United States. More treatment options must be developed for bulky and nodal positive tumors. The selected major phase III studies are summarized in Table 1, and the tumor stages for enrolled patients are in Table 2.

\section{Radiotherapy in the Definitive Treatment of Localized Anal Cancer}

Radiotherapy has been an integral part of organsparing treatment for anal canal carcinoma since the original regimen reported by Nigro et al..$^{23}$ However, different aspects of its planning and delivery continue to evolve, with the goal of improving oncologic outcomes while reducing treatment-related toxicity.

The optimal dose for gross disease and elective nodal drainage areas is controversial. The original regimen used 30 Gy in 15 fractions to the whole pelvis, with concurrent MMC and 5-FU, and produced a clinical complete response rate of $86 \%$. Higher doses were used in the major phase III clinical trials, but published results have not shown a clear advantage. Both RTOG 87-04 and 98-11 called for a total of 45 to 59.4 Gy delivered to gross disease, depending on the clinical stage and initial response to treatment. A modest increase to $92 \%$ in the complete response rate was achieved in RTOG 87-04 with the higher-dose radiation. This was not the case in the EORTC study. The trial reported a clinical complete response rate of $80 \%$ with 60 to 65 Gy delivered with 5-FU. ${ }^{8}$ However, patients in the EORTC study had more advanced disease. Conclusions are difficult to draw based on these data because several confounding factors may influence the clinical outcomes. For example, patients given the highest total doses had very long overall treatment times because of planned delays, meaning accelerated repopulation likely decreased the efficacy of radiotherapy. Additionally, retrospective data are limited associating higher total dose with better relapse-free survival.

The appropriate dose to elective areas is equally controversial. RTOG 87-04 and 98-11 prescribed doses of 30.6, 36, and 45 Gy to different areas of clinically negative nodes depending on their anatomic location. However, the UKCCCR and EORTC trials used doses of 45 Gy to elective nodal stations. Furthermore, the UKCCCR trial did not require elective nodal treatment. Whether nodal failure sig- nificantly differed in these trials is unclear despite the differences in approach to elective areas.

Split-course radiotherapy was frequently used in several previous studies. Both RTOG 92-08 and EORTC 22861 called for a 2-week treatment break in the protocol..$^{10,11}$ The United States investigators concluded that treatment breaks likely result in inferior efficacy of chemoradiation, whereas the European investigators did not find this in their patient population. More recently, the ACT II study reported a high clinical complete response rate (95\%). ${ }^{20}$ The investigators attributed the high efficacy to no treatment break during the radiotherapy.

The recently closed RTOG 05-29 prescribed 42 to 45 Gy to elective areas without lymphadenopathy on imaging, and 50.4 Gy to inguinopelvic lymph nodes smaller than $3 \mathrm{~cm}$. Lymph nodes larger than 3 $\mathrm{cm}$ were given the same dose as the primary (54 Gy). The trial has completed its accrual and results are pending, but will be helpful in properly evaluating the efficacy of a relatively higher dose ( 54 Gy) given without a treatment break.

To improve the accuracy of radiation field design, several measures have been used. The use of PET in treatment planning could potentially decrease toxicity by decreasing the size of the boost field. ${ }^{24}$ Intensity-modulated radiotherapy (IMRT) offers additional theoretical advantages over conventional 2-and 3-dimensional radiotherapy methods through improving dose-conformality to the target. Small institutional series have suggested IMRT can produce less grade 3 to 4 toxicity. ${ }^{25}$ Recently, Salama et al. ${ }^{26}$ published a study using IMRT with MMC and 5-FU in anal carcinoma. A total of 53 patients were treated in the study and followed up for a median of 14.5 months. The authors reported an $83.9 \%$ local control rate and a $93.4 \%$ overall survival rate with manageable toxicities. These results are preliminary but encouraging. RTOG 05-29 will prospectively assess the efficacy and safety of IMRT delivered concurrently with MMC and 5-FU. Currently, a standard radiation technique is difficult to narrowly define based on the diversity of techniques used in the major phase III trials. However, the minimum dose of the boost field should be 45 Gy, and total doses larger than 59 Gy are not standard. 
Jiang et al.

\begin{tabular}{|c|c|c|c|c|c|}
\hline Studies & Sample Size & Regimen & $\begin{array}{l}\text { Disease-Free } \\
\text { Survival }\end{array}$ & Local Failure Rate & Overall Survival \\
\hline $\mathrm{UKCCCR}^{7}$ & 585 & $\begin{array}{l}\text { Radiation vs. } \\
\text { MMC/5-FU } \\
\text { radiation }\end{array}$ & Not provided & $\begin{array}{l}61 \% \text { with } \\
\text { radiation alone } \\
\text { vs. } 39 \% \text { with } \\
\text { chemoradiation at } \\
3 \text { years } \\
P<.001\end{array}$ & $\begin{array}{l}58 \% \text { with } \\
\text { radiation alone } \\
\text { vs. } 65 \% \text { with } \\
\text { chemoradiation } \\
\text { at } 3 \text { years } \\
P=.25\end{array}$ \\
\hline $\begin{array}{l}\text { Flam et al. }{ }^{9} \\
\text { RTOG 87-04 }\end{array}$ & 291 & $\begin{array}{l}\text { 5-FU radiation } \\
\text { vs. MMC/5-FU } \\
\text { radiation }\end{array}$ & $\begin{array}{l}51 \% 5 \text {-FU vs. } \\
73 \% \text { with } 5 \text {-FU/ } \\
\text { MMC at } 4 \text { years } \\
P=.0003\end{array}$ & $\begin{array}{l}\text { Colostomy-free } \\
\text { survival: } \\
59 \% \text { with } 5 \text {-FU vs. } \\
71 \% \text { with } 5 \text {-FU/ } \\
\text { MMC at } 4 \text { years } \\
P=.014 \\
\text { Colostomy rate: } \\
22 \% \text { with } 5-\mathrm{FU} \\
\text { vs. } 9 \% \text { with } 5 \text {-FU/ } \\
\text { MMC } \\
P=.002\end{array}$ & $\begin{array}{l}71 \% \text { with } 5-\mathrm{FU} \\
\text { vs. } 78.1 \% \text { with } \\
5-\mathrm{FU} / \mathrm{MMC} \\
P=.31\end{array}$ \\
\hline $\begin{array}{l}\text { Bartelink et al. }{ }^{8} \\
\text { EORTC }\end{array}$ & 110 & $\begin{array}{l}\text { Radiation vs. } \\
\text { MMC/5-FU } \\
\text { radiation }\end{array}$ & Not provided & $\begin{array}{l}50 \% \text { with } \\
\text { radiation vs. } 32 \% \\
\text { with } 5 \text {-FU/MMC at } \\
5 \text { years* } \\
P=.02\end{array}$ & $\begin{array}{l}54 \% \text { radiation } \\
\text { vs. } 58 \% \text { with } \\
5 \text {-FU/MMC } \\
P=.17\end{array}$ \\
\hline $\begin{array}{l}\text { Ajani et al. }{ }^{14} \\
\text { RTOG 98-11 }\end{array}$ & 644 & $\begin{array}{l}\text { 5-FU/MMC } \\
\text { radiation vs. } \\
\text { 5-FU/CDDP } \\
\text { radiation }\end{array}$ & $\begin{array}{l}60 \% \text { with } 5-\mathrm{FU} / \\
\text { MMC vs. } 54 \% \\
5 \text {-FU/CDDP at } 5 \\
\text { years } \\
P=.17\end{array}$ & $\begin{array}{l}25 \% \text { with } 5-\mathrm{FU} / \\
\text { MMC vs. } 33 \% \text { with } \\
5 \text {-FU/cisplatin } \\
P \text { value not } \\
\text { provided } \\
\text { Colostomy rate: } \\
10 \% \text { with } 5 \text {-FU/ } \\
\text { MMC vs. } 19 \% \text { with } \\
5 \text {-FU/CDDP } \\
P=.02\end{array}$ & $\begin{array}{l}75 \% \text { with } 5-\mathrm{FU}, \\
\text { MMC vs. } 70 \% \\
\text { with } 5-\mathrm{FU} / \\
\text { cisplatin } \\
P=.1\end{array}$ \\
\hline $\begin{array}{l}\text { James et al. }{ }^{20} \\
\text { UKCCCR ACT II }\end{array}$ & 940 & $\begin{array}{l}\text { MMC- or } \\
\text { CDDP-based } \\
\text { chemoradiation } \\
\text { +/- CDDP/5-FU } \\
\text { maintenance }\end{array}$ & $\begin{array}{l}75 \% \text { on both } \\
\text { arms at } 3 \text { years }\end{array}$ & $\begin{array}{l}\text { Equivocal on both } \\
\text { arms ( } 5 \% \text { with } \\
\text { maintenance vs. } \\
4 \% \text { without) }\end{array}$ & $\begin{array}{l}85 \% \text { with } \\
\text { maintenance at } \\
3 \text { years } \\
84 \% \text { without } \\
P \text { value not } \\
\text { significant }\end{array}$ \\
\hline $\begin{array}{l}\text { Conroy et al. }{ }^{21} \\
\text { ACCORD } 03\end{array}$ & 307 & $\begin{array}{l}\text { A: IC + FUP/XRT } \\
+15 \text { Gy } \\
\text { B: IC + FUP/XRT } \\
+20-25 \text { Gy } \\
\text { C: FUP/XRT + } \\
15 \text { Gy } \\
\text { D: FUP/XRT + } \\
20-25 \text { Gy }\end{array}$ & Not provided & $\begin{array}{l}\text { A: } 28 \% \\
\text { B: } 21 \% \\
\text { C: } 30 \% \\
\text { D: } 30 \% \\
P \text { value not } \\
\text { significant }\end{array}$ & $\begin{array}{l}\text { A: } 79 \% \\
\text { B: } 88.5 \% \\
\text { C: } 89 \% \\
\text { D: } 79 \% \\
P \text { value not } \\
\text { significant }\end{array}$ \\
\hline
\end{tabular}

*Estimated from figures in the original paper.

Abbreviations: CDDP, cisplatin; FU, fluorouracil; FUP, cisplatin and 5-FU; IC, induction chemotherapy; MMC, mitomycin; UKCCCR, United Kingdom Coordinating Committee on Cancer Research; XRT, radiation.

\section{Clinical Prognostic Factors}

Clinical stage is the most well-established prognostic factor. Bilimoria et al. ${ }^{27}$ analyzed anal cancer cases from 1985 to 2000 in the National Cancer Data Base. Advanced clinical stage was associated with poor survival. A total of 19,191 patients in the database were analyzed. Overall 5-year survival was $58 \%$, with $69.5 \%$ for stage I, $59 \%$ for stage II, $40.6 \%$ for stage III, and $18.7 \%$ for stage IV. This study confirmed the clinical findings described earlier by others. ${ }^{28} \mathrm{~A}$ retro- 
Anal Carcinoma Therapy

\begin{tabular}{|c|c|c|c|}
\hline Studies & $\begin{array}{l}\text { Percentage of Positive } \\
\text { Nodal Disease }\end{array}$ & Percentage of T1-T2 & Percentage of T3-T4 \\
\hline UKCCCR ${ }^{7}$ & $\begin{array}{l}\text { XRT group: } 17 \% \\
\text { CMT: } 23 \%\end{array}$ & $\begin{array}{l}\text { XRT group: } 48 \% \\
\text { CMT: } 41 \%\end{array}$ & $\begin{array}{l}\text { XRT group: } 51 \% \\
\text { CMT: } 56 \%\end{array}$ \\
\hline $\begin{array}{l}\text { Bartelink et al. }{ }^{8} \\
\text { EORTC }\end{array}$ & $\begin{array}{l}\text { XRT: } 48 \% \\
\text { CMT: } 54.9 \%\end{array}$ & $\begin{array}{l}\text { XRT: } 15.4 \% \\
\text { CMT: } 15.7 \%\end{array}$ & $\begin{array}{l}\text { XRT: } 81 \% \\
\text { CMT: } 84.3 \%\end{array}$ \\
\hline $\begin{array}{l}\text { Flam et al. }{ }^{9} \\
\text { RTOG 87-04 }\end{array}$ & $\begin{array}{l}\text { 5-FU+XRT: } 82 \% \\
\text { 5-FU/MMC+XRT: } 83 \%\end{array}$ & $\begin{array}{l}\text { 5-FU+XRT: } 50 \% \\
\text { 5-FU/MMC+XRT: } 57 \%\end{array}$ & $\begin{array}{l}\text { 5-FU+XRT: } 50 \% \\
\text { 5-FU/MMC+XRT: } 43 \%\end{array}$ \\
\hline $\begin{array}{l}\text { Ajani et al. }{ }^{14} \\
\text { RTOG 98-11 }\end{array}$ & $\begin{array}{l}\text { MMC/5-FU+XRT: } 25 \% \\
\text { Cisplatin/5-FU+XRT: } 26 \%\end{array}$ & $\begin{array}{l}\text { MMC/5-FU+XRT: } 63 \% \\
\text { Cisplatin/5-FU+XRT: } 66 \%\end{array}$ & $\begin{array}{l}\text { MMC/5-FU+XRT: } 37 \% \\
\text { Cisplatin/5-FU+XRT: } 33 \%\end{array}$ \\
\hline $\begin{array}{l}\text { James et al. }{ }^{20} \\
\text { UKCCCR ACT II }\end{array}$ & $\begin{array}{l}\text { Data not provided for each } \\
\text { treatment group } \\
\text { Positive: } 30 \% \\
\text { Negative: } 62 \%\end{array}$ & $50 \%$ & $43 \%$ \\
\hline $\begin{array}{l}\text { Conroy et al. }{ }^{21} \\
\text { ACCORD } 03\end{array}$ & Data not provided & $\begin{array}{l}25 \%-31 \% \text { among } \\
\text { treatment } 4 \text { groups }\end{array}$ & $58 \%-73 \%$ \\
\hline
\end{tabular}

Abbreviations: 5-FU, 5-fluorouracil; CMT, combined modality therapy; MMC, mitomycin; UKCCCR, United Kingdom Coordinating Committee on Cancer Research; XRT, radiation.

spective study from M. D. Anderson Cancer Center also suggested that higher $\mathrm{T}$ and $\mathrm{N}$ stage correlated with poor local control and survival. ${ }^{29}$ A multivariate analysis of EORTC 22861 showed that NO disease has superior local control $(P=.0035)$ and overall survival $(P=.0003) .{ }^{8}$ In the multivariate analysis of RTOG 98-11, tumor size but not nodal status seems to be an independent prognostic feature. ${ }^{30}$

Ajani et al. ${ }^{31}$ showed that patients with tumors greater than $5 \mathrm{~cm}$, irregardless of nodal status, had a higher colostomy rate and inferior disease-free survival. Roohipour et al. ${ }^{32}$ showed that treatment tolerance was important for the outcomes. The authors reviewed 131 anal cancer cases treated at Memorial Sloan-Kettering Cancer Center and found that completion of chemoradiation and the total dose of radiation were significantly associated with treatment failure. Similarly, Deniaud-Alexandre et al..$^{33}$ reviewed 305 patients treated with definitive chemoradiation for anal cancer. The authors reported that complete response is high in T1 (96\%) and T2 (87\%) tumors. Longer treatment break (> 38 days) was associated with a poorer prognosis. In addition, pretreatment sphincter function determined clinical outcome. In general, advanced $\mathrm{T}$ and $\mathrm{N}$ stages, longer radiation treatment break, and resistance to chemoradiation result in inferior survival.

\section{Molecular Prognostic and Predictive Factors}

More recently, prognostic factors were assessed at the molecular level. However, most of the studies have small sample size, and further validation of their results is needed before firm conclusions can be drawn. Perhaps the largest molecular profiling study is that presented recently by Mawdsley et al. ${ }^{34}$ in abstract form at the 2009 ASCO annual meeting. The authors analyzed 240 of 577 tissue samples from the UKCCCR ACT I study for the expression level of p53, Bcl-2, thymidylate synthase (TS), thymidine phosphorylase (TP), and Ki-67. The study showed that high expression level of $\mathrm{p} 53$ was associated with poor prognosis in a multivariate analysis. However, Bcl-2, TS, Ki-67, and TP had no prognostic value.

p53 and Bcl-2 were also assessed in other studies published earlier. Bonin et al. ${ }^{35}$ examined p53 expression in pretreatment tissue samples from 64 patients in RTOG 87-04. p53 protein was expressed in $48.4 \%$ of the tumor specimen. Inferior local control was found in tumors expressing higher level of p53 (local control rate, $52 \%$ in tumors with $>5 \%$ of $\mathrm{p} 53$ vs. $72 \%$ in tumors with $<5 \%$ of $\mathrm{p} 53 ; P=.27)$, with overall survival reflecting the same finding $(58 \%$ for tumors with $>5 \%$ of p53 vs. $78 \%$ for tumors with $<5 \%$ of $\mathrm{p} 53 ; \mathrm{P}=.14)$. Further analysis showed that patients with tumors overexpressing p53 may benefit from MMC and 5-FU chemoradiation. In a Canadian study, Wong et al. ${ }^{36}$ also reported poor survival 
Jiang et al.

rates in patients with high expression levels of p53. Again, this study also showed that disease-free survival was superior in patients with less than 5\% p53 expression. In addition, no correlation between vascular endothelial growth factor (VEGF) expression and microvessel density was seen with disease-free or overall survival.

Bcl-2 is an antiapoptotic protein expressed or dysregulated in many tumor cells. Allal et al. ${ }^{37}$ assessed the expression of $\mathrm{p} 53$ and $\mathrm{Bcl}-2$ in patients with anal cancer treated with 5-FU and mitomycin chemoradiation. A total of 98 pretreatment biopsy samples were assessed for the expression of $\mathrm{p} 53$ and $\mathrm{Bcl}-2$ proteins using immunohistochemistry staining. A trend of negative impact on disease-free survival and local control was observed in patients with an elevated level of p53 in the tumors. However, this trend did not reach statistical significance. A significantly better disease-free survival and local control was observed in tumors expressing $\mathrm{Bcl}-2$. The best local control was observed in the group with $\mathrm{Bcl}-2(+) / \mathrm{p} 53(-)$ (5-year local control: $93 \%$ vs. $53 \% ; P=.004)$.

In a recent publication, Ajani et al. ${ }^{30}$ evaluated a panel of biomarkers, including VEGF, p53, p16, Bcl2, nuclear factor kappa-B (NF-кB), Sonic Hedgehog $(\mathrm{SHH})$, and transcriptional factor Gli-1, in 30 anal cancer specimens at the M. D. Anderson Cancer Center. In the multivariate analysis, tumor size, $\mathrm{Ki}-67$, expression of NF- $\mathrm{kB}, \mathrm{SHH}$, and Gli-1 were significantly associated with disease-free survival. In this study, ex- pression of $\mathrm{p} 53$ did not seem to affect survival. Nilsson et $\mathrm{al}^{38}$ assessed the expression of $\mathrm{p} 53, \mathrm{p} 21$, cyclin A, and CD31 in 215 clinical biopsy samples and showed that only high expression level of cyclin A correlated with an improved survival (77\% vs. 59\%; $P=.005$ ). The authors speculated that tumors with high levels of cyclin A might be more sensitive to radiation. Other biomarkers, such as EGFR expression, amplification and mutation, $\mathrm{k}$-ras mutations, and VEGF expression, did not show strong correlations with survival. Table 3 summarizes selected biomarkers reported in the literature.

In summary, consistent data for molecular prognostic and predictive markers in anal cancer remains lacking, possibly attributable to many studies having small sample sizes. Further studies are needed.

\section{Summary}

The maturation of chemoradiation has changed the treatment paradigm to organ preservation in squamous cell carcinoma of the anal canal. Definitive chemoradiation with $\mathrm{MMC}$ and 5-FU remains standard care for the management of locoregionally confined anal cancer after 2 recent negative phase III trials. The evaluation of novel agents is currently ongoing. Discovering and defining molecular biomarkers that guide treatment are urgently needed to generate better therapeutic strategies.

\section{Table 3 Selected Molecular Biomarkers in Squamous Cell Carcinoma of the Anal Canal}

\begin{tabular}{|c|c|c|}
\hline Studies & Biomarkers/Sample Size & Clinical Outcomes \\
\hline $\begin{array}{l}\text { Bonin et al. }{ }^{35} \\
\text { RTOG } 87-04\end{array}$ & $\begin{array}{l}\text { p53 protein expression in } 64 \text { tissue } \\
\text { samples }\end{array}$ & $\begin{array}{l}\text { Low-level expression }(<5 \%) \text { was associated with } \\
\text { a trend of better disease-free survival and overall } \\
\text { survival. } P \text { value: not significant. }\end{array}$ \\
\hline Allal et al. ${ }^{37}$ & p53 and Bcl-1 in 98 samples & $\begin{array}{l}\text { p53-negative and } \mathrm{Bcl}-2 \text {-positive were associated with } \\
\text { better local control; } P=.004 \text {. }\end{array}$ \\
\hline Mawdsley et al. ${ }^{34}$ & p53, Bcl-2, ki-67, TS in 240 samples & $\begin{array}{l}\text { Only high p53 was associated with poor response and } \\
\text { survival; } P=.011 \text {. }\end{array}$ \\
\hline Ajani et al. ${ }^{30}$ & $\begin{array}{l}\text { p53, VEGF, EGFR, Ki-67, SHH, Gli-1, } \\
\text { NF-KB in } 30 \text { anal cancer samples }\end{array}$ & $\begin{array}{l}\text { Ki-67, SHH, Gli-1, and NF-kB were the independent } \\
\text { prognostic predictors. } \\
\text { p53, VEGF, and EGFR were not prognostic in the } \\
\text { multivariate analysis. }\end{array}$ \\
\hline Nilsson et al. ${ }^{38}$ & $\begin{array}{l}\text { Cyclin A, p53, p21, CD31 in } 215 \\
\text { samples }\end{array}$ & $\begin{array}{l}\text { Low p21 was associated with reduced local failure } \\
(P<.05) . \\
\text { p53 and CD31 had no correlation with survival. } \\
\text { High cyclin A level was associated with better survival } \\
(P=.009) .\end{array}$ \\
\hline
\end{tabular}

Abbreviations: EGFR, epidermal growth factor receptor; SHH, Sonic Hedgehog; TS, thymidine synthase; VEGR, vascular endothelial growth factor. 


\section{References}

1. Horner MJ, Ries LA, Krapcho M, et al. SEER Cancer Statistics Review, 1975-2006. Available at: http://seercancergov/ csr/1975_2006/. Accessed November 23, 2009.

2. Greenall MJ, Quan SH, Urmacher C, DeCosse JJ. Treatment of epidermoid carcinoma of the anal canal. Surg Gynecol Obstet 1985;161:509-517.

3. Beahrs $\mathrm{OH}$, Wilson SM. Carcinoma of the anus. Ann Surg 1976;184:422-428.

4. Boman BM, Moertel CG, O'Connell MJ, et al. Carcinoma of the anal canal. A clinical and pathologic study of 188 cases. Cancer 1984;54:114-125.

5. Hardcastle JD, Bussey HJ. Results of surgical treatment of squamous cell carcinoma of the anal canal and anal margin seen at St. Mark's Hospital 1928-66. Proc R Soc Med 1968;61:629-630.

6. Nigro ND, Seydel HG, Considine B, et al. Combined preoperative radiation and chemotherapy for squamous cell carcinoma of the anal canal. Cancer 1983;51:1826-1829.

7. Epidermoid anal cancer: results from the UKCCCR randomised trial of radiotherapy alone versus radiotherapy, 5-fluorouracil, and mitomycin. UKCCCR Anal Cancer Trial Working Party. UK Co-ordinating Committee on Cancer Research. Lancet 1996;348:1049-1054.

8. Bartelink H, Roelofsen F, Eschwege F, et al. Concomitant radiotherapy and chemotherapy is superior to radiotherapy alone in the treatment of locally advanced anal cancer: results of a phase III randomized trial of the European Organization for Research and Treatment of Cancer Radiotherapy and Gastrointestinal Cooperative Groups. J Clin Oncol 1997;15:2040-2049.

9. Flam M, John M, Pajak TF, et al. Role of mitomycin in combination with fluorouracil and radiotherapy, and of salvage chemoradiation in the definitive nonsurgical treatment of epidermoid carcinoma of the anal canal: results of a phase III randomized intergroup study. J Clin Oncol 1996;14:2527-2539.

10. Bosset JF, Roelofsen F, Morgan DA, et al. Shortened irradiation scheme, continuous infusion of 5-fluorouracil and fractionation of mitomycin C in locally advanced anal carcinomas. Results of a phase II study of the European Organization for Research and Treatment of Cancer. Radiotherapy and Gastrointestinal Cooperative Groups. Eur J Cancer 2003;39:45-51.

11. John M, Pajak T, Flam M, et al. Dose escalation in chemoradiation for anal cancer: preliminary results of RTOG 92-08. Cancer J Sci Am 1996;2:205-211.

12. Konski A, Garcia M Jr, John M, et al. Evaluation of planned treatment breaks during radiation therapy for anal cancer: update of RTOG 92-08. Int J Radiat Oncol Biol Phys 2008;72:114-118.

13. Doci R, Zucali R, La Monica G, et al. Primary chemoradiation therapy with fluorouracil and cisplatin for cancer of the anus: results in 35 consecutive patients. J Clin Oncol 1996;14:3121-3125.

14. AjaniJA, Winter KA, Gunderson LL, et al. Fluorouracil, mitomycin, and radiotherapy vs fluorouracil, cisplatin, and radiotherapy for carcinoma of the anal canal: a randomized controlled trial. JAMA 2008;299:1914-1921.

15. Matzinger $\mathrm{O}$, Roelofsen F, Mineur L, et al. Mitomycin $\mathrm{C}$ with continuous fluorouracil or with cisplatin in combination with radiotherapy for locally advanced anal cancer (European Organisation for Research and Treatment of Cancer phase II study 22011-40014). Eur J Cancer 2009;45:2782-2791.
16. Bonner JA, Harari PM, Giralt J, et al. Radiotherapy plus cetuximab for squamous-cell carcinoma of the head and neck. N Engl J Med 2006;354:567-578.

17. Olivatto LO, Meton F, Bezerra M, et al. Phase I study of cetuximab (CET) in combination with 5-fluorouracil (5-FU), cisplatin (CP), and radiotherapy (RT) in patients with locally advanced squamous cell anal carcinoma (LAAC) [abstract]. J Clin Oncol 2008;26(Suppl 1):Abstract 4609.

18. Eng C, Chang GJ, Das P, et al. Phase II study of capecitabine and oxaliplatin with concurrent radiation therapy (XELOX-XRT) for squamous cell carcinoma of the anal canal [abstract]. J Clin Oncol 2009;27(Suppl 1):Abstract 4116.

19. James R, Cunningham D, Davidson N, et al. Chemoradiation and maintenance chemotherapy for patients with anal carcinoma: a phase II trial of the UK Co-Ordinating Committee for Cancer Research (UKCCCR) Anal Cancer Trial Working Party [abstract]. Proc Am Soc Clin Oncol 2000;19:Abstract 1045.

20. James R, Wan S, Glynne-Jones R, et al. A randomized trial of chemoradiation using mitomycin or cisplatin, with or without maintenance cisplatin/5FU in squamous cell carcinoma of the anus (ACT II) [abstract]. J Clin Oncol 2009;27(Suppl 1):Abstract LBA4009.

21. Conroy T, Ducreux M, Lemanski C, et al. Treatment intensification by induction chemotherapy (ICT) and radiation dose escalation in locally advanced squamous cell anal canal carcinoma (LAAC): definitive analysis of the intergroup ACCORD 03 trial [abstract]. J Clin Oncol 299;27(Suppl 1):Abstract 4033.

22. Meropol NJ, Niedzwiecki D, Shank B, et al. Induction therapy for poor-prognosis anal canal carcinoma: a phase II study of the Cancer and Leukemia Group B (CALGB 9281). J Clin Oncol 2008;26:3229-3234.

23. Nigro ND, Vaitkevicius VK, Considine B Jr. Combined therapy for cancer of the anal canal: a preliminary report. Dis Colon Rectum 1974;17:354-356.

24. Anderson C, Koshy M, Staley C, et al. PET-CT fusion in radiation management of patients with anorectal tumors. Int J Radiat Oncol Biol Phys 2007;69:155-162.

25. Milano MT, Jani $A B$, Farrey $K J$, et al. Intensity-modulated radiation therapy (IMRT) in the treatment of anal cancer: toxicity and clinical outcome. Int J Radiat Oncol Biol Phys 2005;63:354361.

26. Salama JK, Mell LK, Schomas DA, et al. Concurrent chemotherapy and intensity-modulated radiation therapy for anal canal cancer patients: a multicenter experience. J Clin Oncol 2007;25:45814586.

27. Bilimoria KY, Bentrem DJ, Rock CE, et al. Outcomes and prognostic factors for squamous-cell carcinoma of the anal canal: analysis of patients from the National Cancer Data Base. Dis Colon Rectum 2009;52:624-631.

28. Schlienger M, Krzisch C, Pene F, et al. Epidermoid carcinoma of the anal canal treatment results and prognostic variables in a series of 242 cases. Int J Radiat Oncol Biol Phys 1989;17:1141-1151.

29. Das P, Bhatia S, Eng C, et al. Predictors and patterns of recurrence after definitive chemoradiation for anal cancer. Int J Radiat Oncol Biol Phys 2007;68:794-800.

30. Ajani JA, Wang X, Izzo JG, et al. Molecular biomarkers correlate with disease-free survival in patients with anal canal carcinoma treated with chemoradiation. Dig Dis Sci, 2009; in press.

31. Ajani JA, Winter KA, Gunderson LL, et al. US intergroup anal carcinoma trial: tumor diameter predicts for colostomy. J Clin Oncol 2009;27:1116-1121. 
Jiang et al.

32. Roohipour R, Patil S, Goodman KA, et al. Squamous-cell carcinoma of the anal canal: predictors of treatment outcome. Dis Colon Rectum 2008;51:147-153.

33. Deniaud-Alexandre E, Touboul E, Tiret E, et al. Results of definitive irradiation in a series of 305 epidermoid carcinomas of the anal canal. Int J Radiat Oncol Biol Phys 2003;56:1259-1273.

34. Mawdsley S, Meadows HM, Royston P, et al. Role of molecular markers in the clinical outcome and prediction of response to treatment in squamous anal cancer [abstract]. Proc Am Soc Clin Oncol 2003;22:Abstract 3566.

35. Bonin SR, Pajak TF, Russell AH, et al. Overexpression of p53 protein and outcome of patients treated with chemoradiation for carcinoma of the anal canal: a report of randomized trial RTOG 87 04. Radiation Therapy Oncology Group. Cancer 1999;85:12261233.

36. Wong CS, Tsao MS, Sharma V, et al. Prognostic role of $\mathrm{p} 53$ protein expression in epidermoid carcinoma of the anal canal. Int J Radiat Oncol Biol Phys 1999;45:309-314.

37. Allal AS, Waelchli L, Brundler MA. Prognostic value of apoptosisregulating protein expression in anal squamous cell carcinoma. Clin Cancer Res 2003;9:6489-6496.

38. Nilsson PJ, Lenander C, Rubio C, et al. Prognostic significance of cyclin A in epidermoid anal cancer. Oncol Rep 2006;16:443-449. 